\title{
Prevention of Mandibular Third Molar Extraction-Associated Periodontal Defects: A Comparative Study
}

\author{
Gilberto Sammartino, ${ }^{*}$ Mariano Tia, ${ }^{*}$ Tommaso Bucci, ${ }^{\dagger}$ and Hom-Lay Wang ${ }^{\ddagger}$
}

Background: Extraction of deep-impacted mandibular third molars may lead to periodontal defects at the distal surface of the adjacent second molar. The purpose of this study was to compare the ability of three regenerative approaches to prevent third molar extraction-related periodontal defects.

Methods: Forty-five patients with bilateral osseous or soft tissue-impacted lower third molars were selected to participate in the study. Inclusion criteria were the presence of a pocket that was located distally to the mandibular second molar with a probing depth (PD) $\geq 7 \mathrm{~mm}$ and with a probing clinical attachment level (CAL) $\geq 6 \mathrm{~mm}$. Ninety third molar impactions were used and were randomly assigned to three equal treatment groups (30 each): bovine porous bone mineral (BPBM) alone, BPBM plus collagen membrane (CM), and an untreated control group. Clinical and radiographic measurements were recorded at $3,6,9,12,18,24,36,48$, 60 , and 72 months after the surgery.

Results: BPBM or BPBM + CM resulted in a significant reduction in PD and gain in CAL compared to the control group at all time points. BPBM + CM had the best outcome for the prevention of a second-molar periodontal defect.

Conclusion: The application of BPBM, with or without a collagen membrane, can be a viable and stable treatment to alleviate the periodontal defects that are often associated with impacted mandibular third molar extractions. J Periodontol 2009;80:389-396.

\section{KEY WORDS}

Alloplast; bone graft; extraction; third molar; tooth impaction.

\footnotetext{
* Department of Oral and Maxillofacial Sciences, University of Naples "Federico II," Naples, Italy.

† Department of Maxillofacial Surgery, Hospital Maragnon of Madrid, Madrid, Spain

₹ Graduate Periodontics, Department of Periodontics and Oral Medicine, University of Michigan, Ann Arbor, MI.
}

Whe presence of deep-impacted and irregular lower third molars often leads to periodontal defects next to the extraction tooth, which often require surgical intervention. ${ }^{1-3}$

A small benefit may be derived from performing root planing on the distal root of the tooth adjacent to the impacted third molar after the extraction. ${ }^{3}$ Some investigators $^{3-5}$ even demonstrated that different flap designs for removing the impacted third molar can result in reduction of the probing depth at the distal surface of the adjacent second molar. Conversely, guided bone regeneration techniques with non-resorbable or bioabsorbable membranes were demonstrated to be a valid aid in the prevention of these periodontal defects. ${ }^{6,7}$

Bone grafts to fill the extraction socket have long been discussed and showed some promising results. ${ }^{8,9}$ Bovine porous bone mineral (BPBM) $)^{\S}$ was selected because of its safety, high biocompatibility, and the highly porous nature of the particles, which can promote cell adhesion and differentiation. ${ }^{10-12}$ This material also has sufficient consistency to support and maintain the space that is essential for bone regeneration. Furthermore, it can also be used to support the overlying bioabsorbable membrane. A collagen membranell (CM) was selected because it has excellent biocompatibility and is easy to handle, bioabsorbable (no

$\S$ Bio-Oss, Geistlich Biomaterials, Wolhusen, Switzerland. || Bio-Gide, Geistlich Biomaterials.

doi: 10.1902/jop.2009.080503 
need for retrieval surgery), and long lasting in relation to the adequate functional integrity time (resorption time of 4 to 6 months). ${ }^{10,13-16}$

The aim of this clinical study was to evaluate the long-term efficacy of using BPBM or BPBM plus a bioabsorbable CM (BPBM + CM) for the prevention of second-molar periodontal defects after extraction of an adjacent deep-impacted lower third molar.

\section{MATERIALS AND METHODS}

\section{Patient Selection}

Forty-five non-smoking patients, 25 males and 20 females aged between 21 and 30 years, with soft tissue or osseous impacted bilateral lower third molars in a mesio-angular or horizontal position were selected for the study. All patients were selected at the Department of Oral and Maxillofacial Sciences, Naples University "Federico II," from January 2000 to January 2001. Ninety third molar impactions were randomly assigned to the three groups: BPBM alone, BPBM + $C M$, and untreated control group. This resulted in three combinations of pairs ( 15 pairs for each combination). Clinical and radiographic measurements were recorded at $3,6,9,12,18,24,36,48,60$, and 72 months after the surgery. Inclusion criteria were the presence of a pocket that was located distally to the mandibular second molar, with a probing depth (PD) $\geq 7 \mathrm{~mm}$ and a probing clinical attachment level $(C A L) \geq 6 \mathrm{~mm}$. Nevertheless, the postextraction defect needed to have intact buccal and lingual cortical bone to ensure standard defect selection. The exclusion criteria were the presence of systemic diseases; a compromised immune system; allergies or hypersensitivity to drugs; or the use of antibiotics, antimicrobials, anti-inflammatory, or cortisone medication in the 12 months preceding the surgery. All patients were informed about the characteristics and the objective of the study and signed an informed consent that was reviewed and approved by the Committees for the Protection of Human Subjects and Scientific Review. This study and the patient's informed consent were approved by University of Naples "Federico II" Institutional Review Board.

\section{Presurgical Therapy and Clinical Measurements}

Prior to surgery, all patients received oral hygiene instructions to attain $\leq 25 \%$ O'Leary plaque index. ${ }^{17} \mathrm{An}$ orthopantomograph and periapical radiograph using the Rinn alignment system were taken of all participants. Plaque index and gingival bleeding index were recorded immediately before surgery and at each follow-up visit. ${ }^{18,19}$ Measurements of PD, CAL, and gingival recession (GR) were made using cold resin occlusal stents taken from a model that was obtained from an alginate cast. These stents were made to cover the occlusal surface and the coronal third por-

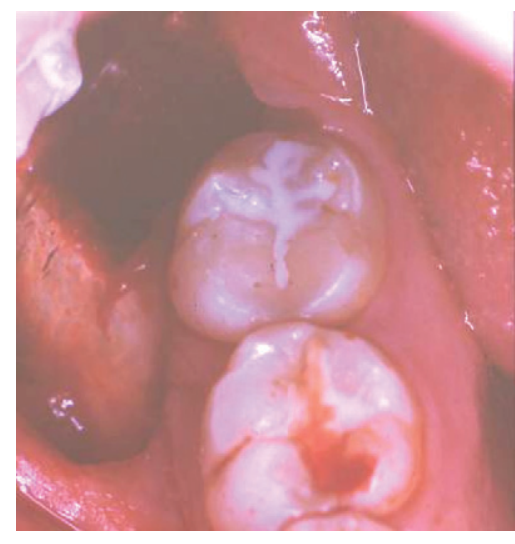

Figure I.

The bone cavity after deep-impacted lower third molar extraction.

tion on the buccal and lingual side of the lower second molar adjacent to the site to be treated. Grooves were made in the resin stents so repeated measurements could be conducted during the study period. The measurements were taken with a Marquis periodontal probell in three different positions (disto-vestibular, distal, and disto-lingual) for all lower second molars and then averaged. PD, CAL, and GR were recorded every 3 months during year 1 , every 6 months during year 2 , and every 12 months for the remaining 4 years.

\section{Surgical Procedure}

After profound anesthesia, a full-thickness mucoperiosteal flap was raised for extraction of the third molar. The flap incision extended from the buccal side of the retromolar region to the marginal periodontal portion of the disto-lingual cusp of the second molar. The incision continued vestibularly around the intrasulcular surface of the second molar and proceeded with a release incision that originated distally to the papilla between the first and second molar, with $\sim 45^{\circ}$ inclination, and extending in the buccal mucosa for 2 to $3 \mathrm{~cm}$. After flap reflection, an osteotomy was performed with a Lindemann bur and constant irrigation; subsequently, an odontotomy was performed using diamond burs on the impacted portion to avoid damage to the adjacent buccal and lingual cortical plate. Osseous surgery was generally not performed. An osseoplasty was conducted to eliminate potential residual defects if a buccal or lingual widow's peak was noted. The residual bone cavity was curetted after extraction of the impacted third molar, and scaling and root planing of the adjacent second molar's distal surface, limited to the diseased root surface, as delineated by the apical extension of calculus (Fig. 1), was performed using manual instruments. The bone cavity was randomly assigned (by picking a paper from a brown bag) to

Il Marquis Dental, Aurora, CO. 
one of the three treatment approaches ( $\mathrm{n}=30$ each): untreated control group, 0.25- to 1-mm particles of BPBM, or BPBM + CM.

BPBM was placed and condensed with amalgam plugger to the bony defect as well as the adjacent second molar (Fig. 2). In the cases in which the membrane was used, it was trimmed to cover the defect $4 \mathrm{~mm}$ beyond the buccal and lingual defects and firmly adapted to the defect and the distal surface of the second molar to avoid mobility. Only scaling and root planing of the second molar was performed in the control group. Then the flap was closed using silk 4-0 sutures that were removed 10 days later. The patients were administered antibiotics (amoxicillin and clavulanic acid, every 12 hours for 8 days), oral anti-inflammatory therapy (ibuprofen, $800 \mathrm{mg}$, every day for 3 days), and $0.12 \%$ chlorhexidine gluconate rinse every 12 hours for 10 days. An oral hygiene check-up and periodontal support therapy were provided for all patients at 2, 4, and 6 weeks after surgery.

\section{Reentry and Histologic Procedure}

All patients had a routine orthopantomograph and a periapical radiograph using the Rinn alignment system $3,6,9,12,18,24,36,48,60$, and 72 months after surgery to evaluate the long-term results (Figs. 3 and 4). Six months after treatment (BPBM and BPBM + CM groups), a second surgery was performed using a core drill with constant irrigation to harvest a bone core of 0.5 $\mathrm{cm}$ from the center of the treated area to assess the degree of bone formation. The sample was fixed with $10 \%$ buffered formalin, demineralized with chloridric acid/formic acid for 48 hours, decalcified in nitric acid, processed routinely, and embedded in paraffin. Sections of the sample (5 $\mu \mathrm{m}$ thick) were stained with acid fuchsin and toluidine blue. All surgeries were done by one surgeon (MT), and a masked examiner (TB) collected all clinical measurements. Histologic analysis was done in a masked manner: the person who performed it did not know from which group the sample had come. Intraexaminer calibration was achieved following the clinical measurement of patients twice: 48 hours after the surgery and immediately before the beginning of the study. Calibration was accepted if the two clinical measurements were within $1 \mathrm{~mm}$ in $>92 \%$ of cases.
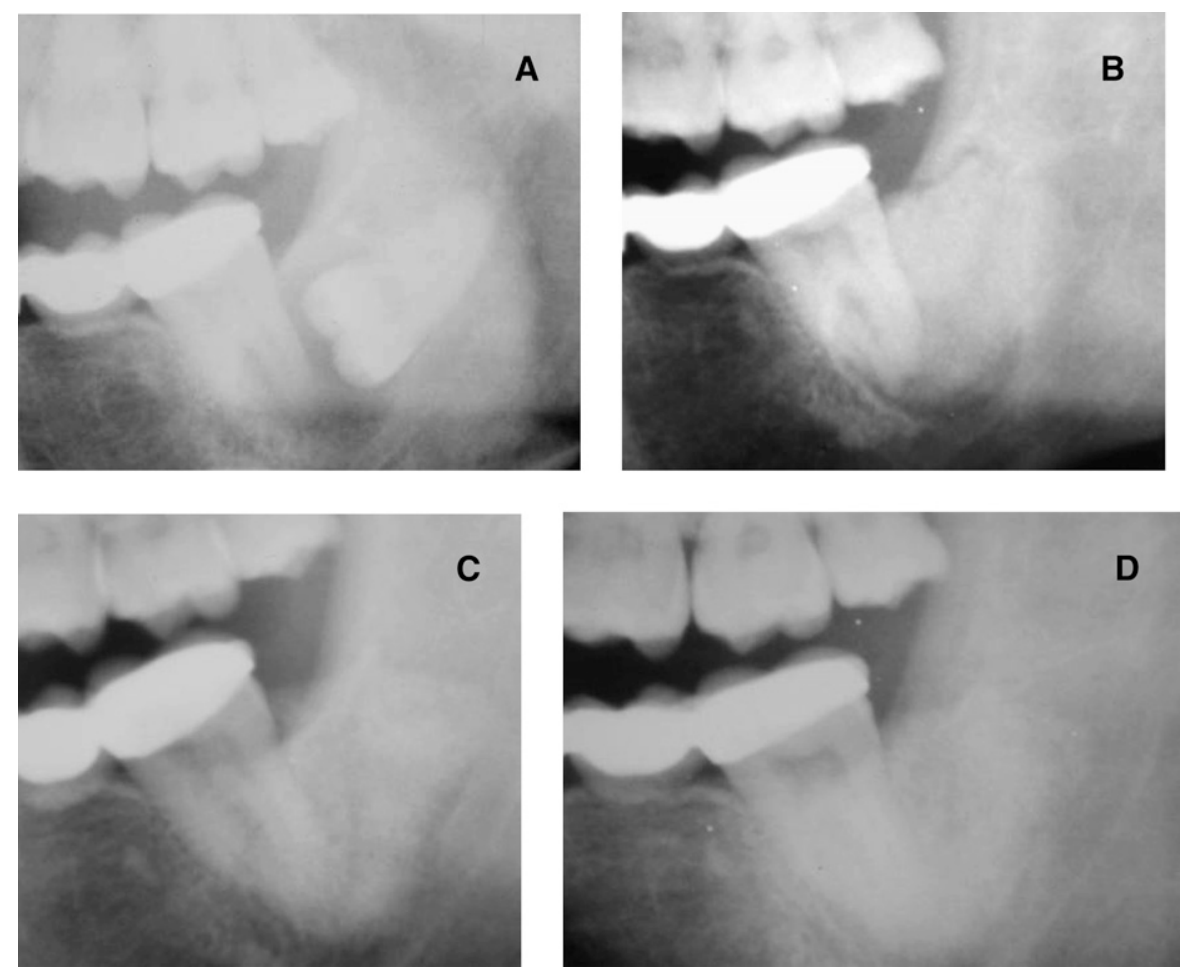

Figure 3.

The deep impaction of the lower third molar causes a periodontal defect to the second molar. A) Before treatment. B) Three months after BPBM + CM treatment. C) Six months after treatment. D) Seventy-two months after the regeneration. 

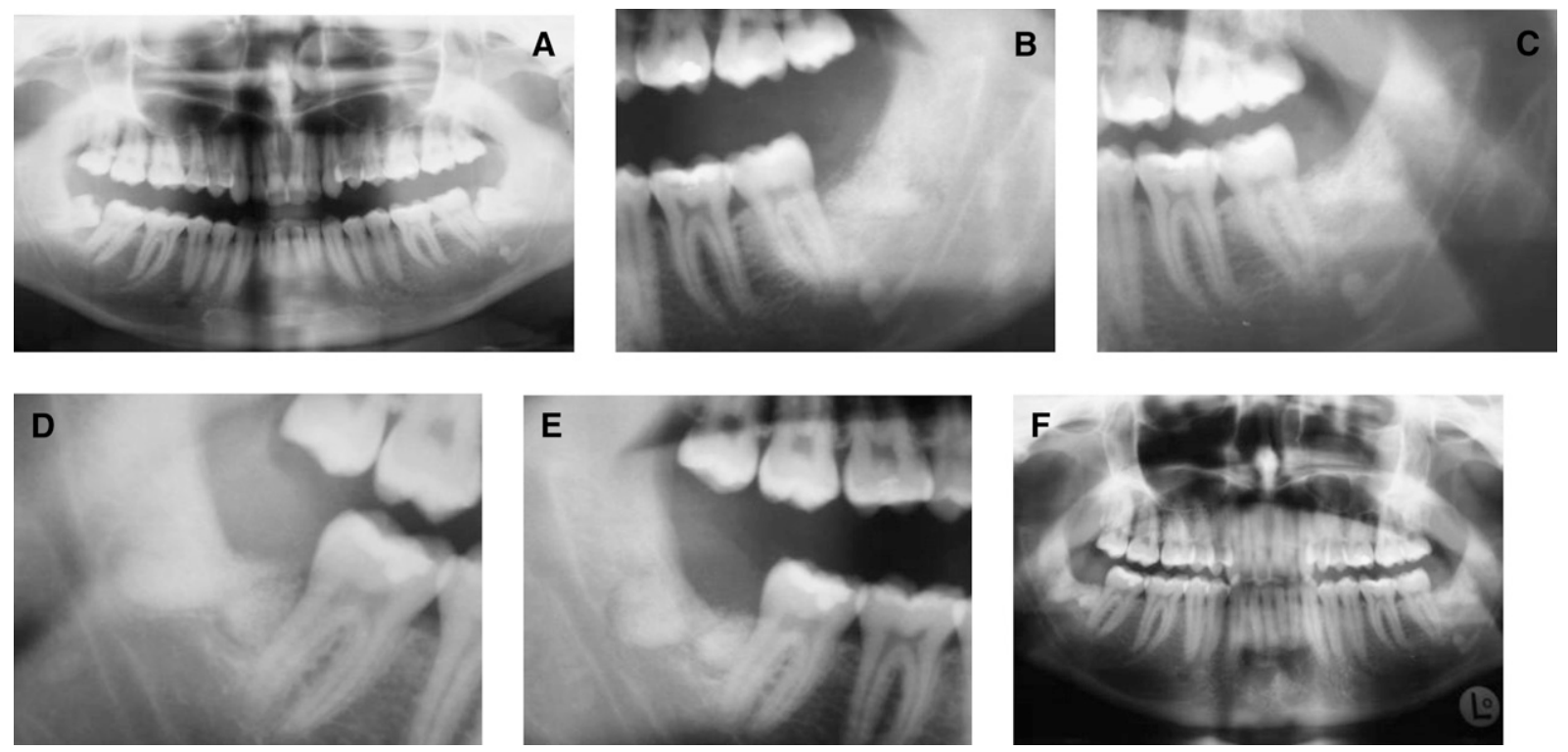

Figure 4.

A) BPBM was used to treat a right third molar postextraction defect, and BPBM + CM was used to treat a left third molar postextraction defect. B) Six months after the treatment with BPBM + CM. C) Twenty-four months after the treatment on the left side. D) Six months after treatment with BPBM. E) Twenty-four months after the treatment on the right side. F) Orthopantomograph 24 months after the bilateral treatment.

Table I.

PD (mm; mean \pm SD) at the Distal Surface of the Lower Second Molar

\begin{tabular}{|c|c|c|c|c|c|c|c|}
\hline Months & $\begin{array}{l}\text { Control } \\
\text { Group } \\
(n=30)\end{array}$ & $\begin{array}{l}\text { BPBM } \\
\text { Group } \\
(n=30)\end{array}$ & $\begin{array}{c}\text { BPBM + CM } \\
\text { Group } \\
(n=30)\end{array}$ & $P$ Value & $\begin{array}{l}\text { Difference Between } \\
\text { Control and } \\
\text { BPBM Groups }\end{array}$ & $\begin{array}{l}\text { Difference Between } \\
\text { Control and } \\
\text { BPBM + CM Groups }\end{array}$ & $\begin{array}{c}\text { Difference Between } \\
\text { BPBM and } \\
\text { BPBM + CM Groups }\end{array}$ \\
\hline 0 (baseline) & $7.68 \pm 0.56$ & $7.60 \pm 0.55$ & $7.66 \pm 0.55$ & $>0.05 \mathrm{NS}$ & & & \\
\hline 3 & $6.56 \pm 0.54$ & $4.49 \pm 0.51$ & $3.87 \pm 0.56$ & $<0.05^{*}$ & $2.07 \pm 0.75$ & $2.69 \pm 0.89$ & $0.62 \pm 0.63$ \\
\hline 6 & $6.48 \pm 0.53$ & $4.10 \pm 0.69$ & $3.53 \pm 0.39$ & $<0.05 *$ & $2.38 \pm 0.91$ & $2.95 \pm 0.66$ & $0.57 \pm 0.71$ \\
\hline 9 & $6.46 \pm 0.52$ & $3.98 \pm 0.60$ & $3.29 \pm 0.31$ & $<0.05^{*}$ & $2.48 \pm 0.83$ & $3.17 \pm 0.61$ & $0.69 \pm 0.63$ \\
\hline 12 & $6.40 \pm 0.53$ & $3.85 \pm 0.54$ & $3.08 \pm 0.33$ & $<0.05 *$ & $2.55 \pm 0.80$ & $3.32 \pm 0.62$ & $0.77 \pm 0.75$ \\
\hline 18 & $6.35 \pm 0.52$ & $3.79 \pm 0.50$ & $3.09 \pm 0.27$ & $<0.05^{*}$ & $2.56 \pm 0.79$ & $3.26 \pm 0.56$ & $0.70 \pm 0.51$ \\
\hline 24 & $6.36 \pm 0.51$ & $3.80 \pm 0.50$ & $3.09 \pm 0.26$ & $<0.05^{*}$ & $2.44 \pm 0.76$ & $3.27 \pm 0.54$ & $0.71 \pm 0.50$ \\
\hline 36 & $6.34 \pm 0.52$ & $3.84 \pm 0.46$ & $3.10 \pm 0.26$ & $<0.05^{*}$ & $2.50 \pm 0.76$ & $3.24 \pm 0.54$ & $0.74 \pm 0.44$ \\
\hline 48 & $6.35 \pm 0.50$ & $3.85 \pm 0.45$ & $3.11 \pm 0.27$ & $<0.05^{*}$ & $2.50 \pm 0.74$ & $3.24 \pm 0.53$ & $0.74 \pm 0.43$ \\
\hline 60 & $6.38 \pm 0.51$ & $3.87 \pm 0.43$ & $3.13 \pm 0.20$ & $<0.05^{*}$ & $2.49 \pm 0.68$ & $3.25 \pm 0.53$ & $0.74 \pm 0.44$ \\
\hline 72 & $6.40 \pm 0.51$ & $3.88 \pm 0.45$ & $3.15 \pm 0.20$ & $<0.05^{*}$ & $2.28 \pm 0.69$ & $3.25 \pm 0.57$ & $0.73 \pm 0.43$ \\
\hline
\end{tabular}

NS = not statistically significant.

* Statistically significant. 
Table 2.

\section{CAL (mm; mean \pm SD) at the Distal Surface of the Lower Second Molar}

\begin{tabular}{|c|c|c|c|c|c|c|c|}
\hline Months & $\begin{array}{l}\text { Control } \\
\text { Group } \\
(n=30)\end{array}$ & $\begin{array}{l}\text { BPBM } \\
\text { Group } \\
(n=30)\end{array}$ & $\begin{array}{c}\text { BPBM }+C M \\
\text { Group } \\
(n=30)\end{array}$ & $P$ Value & $\begin{array}{l}\text { Difference Between } \\
\text { Control and } \\
\text { BPBM Groups }\end{array}$ & $\begin{array}{l}\text { Difference Between } \\
\text { Control and } \\
\text { BPBM + CM Groups }\end{array}$ & $\begin{array}{c}\text { Difference Between } \\
\text { BPBM and } \\
\text { BPBM + CM Groups }\end{array}$ \\
\hline 0 (baseline) & $6.42 \pm 0.61$ & $6.45 \pm 0.61$ & $6.45 \pm 0.61$ & $>0.05 \mathrm{NS}$ & & & \\
\hline 3 & $6.31 \pm 0.59$ & $4.31 \pm 0.66$ & $3.59 \pm 0.64$ & $<0.05^{*}$ & $2.00 \pm 0.66$ & $2.72 \pm 0.62$ & $0.72 \pm 0.52$ \\
\hline 6 & $6.26 \pm 0.60$ & $3.96 \pm 0.64$ & $3.28 \pm 0.47$ & $<0.05 *$ & $2.30 \pm 0.58$ & $2.98 \pm 0.57$ & $0.68 \pm 0.56$ \\
\hline 9 & $6.23 \pm 0.59$ & $3.79 \pm 0.53$ & $3.09 \pm 0.37$ & $<0.05^{*}$ & $2.44 \pm 0.59$ & $3.14 \pm 0.59$ & $0.70 \pm 0.51$ \\
\hline 12 & $6.20 \pm 0.57$ & $3.63 \pm 0.50$ & $2.89 \pm 0.34$ & $<0.05^{*}$ & $2.57 \pm 0.61$ & $3.31 \pm 0.63$ & $0.74 \pm 0.57$ \\
\hline 18 & $6.19 \pm 0.58$ & $3.50 \pm 0.49$ & $2.84 \pm 0.34$ & $<0.05^{*}$ & $2.69 \pm 0.57$ & $3.35 \pm 0.61$ & $0.72 \pm 0.48$ \\
\hline 24 & $6.14 \pm 0.58$ & $3.50 \pm 0.48$ & $2.85 \pm 0.30$ & $<0.05^{*}$ & $2.64 \pm 0.58$ & $3.29 \pm 0.60$ & $0.69 \pm 0.48$ \\
\hline 36 & $6.14 \pm 0.55$ & $3.53 \pm 0.47$ & $2.83 \pm 0.21$ & $<0.05^{*}$ & $2.61 \pm 0.58$ & $3.31 \pm 0.55$ & $0.74 \pm 0.48$ \\
\hline 48 & $6.11 \pm 0.54$ & $3.52 \pm 0.45$ & $2.84 \pm 0.20$ & $<0.05^{*}$ & $2.61 \pm 0.56$ & $3.27 \pm 0.56$ & $0.75 \pm 0.42$ \\
\hline 60 & $6.09 \pm 0.55$ & $3.53 \pm 0.48$ & $2.87 \pm 0.20$ & $<0.05 *$ & $2.66 \pm 0.56$ & $3.22 \pm 0.54$ & $0.75 \pm 0.47$ \\
\hline 72 & $6.09 \pm 0.57$ & $3.54 \pm 0.49$ & $2.89 \pm 0.22$ & $<0.05^{*}$ & $2.65 \pm 0.58$ & $3.20 \pm 0.57$ & $0.74 \pm 0.46$ \\
\hline
\end{tabular}

NS = not statistically significant.

* Statistically significant.

\section{Statistical Analysis}

Statistical analysis was performed using statistical software. ${ }^{*}$ Measurements were performed in triplicate and averaged to obtain the final value for PD and CAL. This reduced any potential measurement errors. Data were calculated and reported as mean \pm $\mathrm{SD}$, and the significance level was set at $P<0.05$. Because of the paired and unpaired nature of this study, repeated-measures analysis of variance (ANOVA) was used to detect the treatment and time effect among all three groups. The paired-sample $t$ test was used to compare between pairs and between two different time points.

\section{RESULTS}

All subjects completed the study. The PD measurements for the untreated control, BPBM, and BPBM + $C M$ sites were $6.56 \pm 0.54 \mathrm{~mm}, 4.49 \pm 0.51 \mathrm{~mm}$, and $3.87 \pm 0.56 \mathrm{~mm}$, respectively, at 3 months after surgery and $6.40 \pm 0.51 \mathrm{~mm}, 3.88 \pm 0.45 \mathrm{~mm}$, and $3.15 \pm 0.20 \mathrm{~mm}$, respectively, at 72 months posttreatment. This was equal to $0.62 \pm 0.63 \mathrm{~mm}, 2.07 \pm$ $0.75 \mathrm{~mm}$, and $2.69 \pm 0.89 \mathrm{~mm}$ of PD reduction at 3 months and $0.73 \pm 0.43 \mathrm{~mm}, 2.28 \pm 0.69 \mathrm{~mm}$, and $3.25 \pm 0.58 \mathrm{~mm}$ of PD reduction at 72 months for the untreated control, BPBM, and BPBM + CM groups, respectively. A statistically significant PD reduction was noted when the two treated groups were compared to the untreated control group. Furthermore, the BPBM + CM group showed a statistically sig-
Table 3.

\section{GR (mm; mean $\pm \mathrm{SD}$ ) at the Distal Surface of the Lower Second Molar}

\begin{tabular}{|c|c|c|c|c}
\hline Months & $\begin{array}{c}\text { BPBM } \\
(n=30)\end{array}$ & $\begin{array}{c}\text { BPBM }+\mathrm{CM} \\
(n=30)\end{array}$ & $\begin{array}{c}\text { Control } \\
\text { Group } \\
(n=30)\end{array}$ & $P$ Value \\
\hline Baseline & $0.93 \pm 0.89$ & $0.92 \pm 1.06$ & $1.02 \pm 0.54$ & $>0.05 \mathrm{NS}$ \\
\hline 3 & $0.97 \pm 0.92$ & $0.93 \pm 1.09$ & $1.01 \pm 0.57$ & $>0.05 \mathrm{NS}$ \\
\hline 6 & $1.01 \pm 1.03$ & $0.96 \pm 0.92$ & $1.04 \pm 0.56$ & $>0.05 \mathrm{NS}$ \\
\hline 9 & $0.96 \pm 0.92$ & $1.01 \pm 0.95$ & $1.03 \pm 0.55$ & $>0.05 \mathrm{NS}$ \\
\hline 12 & $0.93 \pm 0.91$ & $1.02 \pm 0.97$ & $1.06 \pm 0.58$ & $>0.05 \mathrm{NS}$ \\
\hline 18 & $0.88 \pm 0.88$ & $0.96 \pm 0.99$ & $1.00 \pm 0.59$ & $>0.05 \mathrm{NS}$ \\
\hline 24 & $0.85 \pm 0.92$ & $0.97 \pm 0.93$ & $1.04 \pm 0.58$ & $>0.05 \mathrm{NS}$ \\
\hline 36 & $0.84 \pm 0.92$ & $0.94 \pm 0.92$ & $1.06 \pm 0.60$ & $>0.05 \mathrm{NS}$ \\
\hline 48 & $0.82 \pm 0.89$ & $0.94 \pm 0.91$ & $1.02 \pm 0.62$ & $>0.05 \mathrm{NS}$ \\
\hline 60 & $0.81 \pm 0.90$ & $0.95 \pm 0.89$ & $0.97 \pm 0.66$ & $>0.05 \mathrm{NS}$ \\
\hline 72 & $0.81 \pm 0.90$ & $0.95 \pm 0.90$ & $0.95 \pm 0.66$ & $>0.05 \mathrm{NS}$ \\
\hline
\end{tabular}

$\mathrm{NS}=$ no statistically significant difference was found for any comparison.

nificant PD reduction compared to the BPBM group $(P<0.05)$ (Table 1$)$.

\# SPSS 13.0 for Windows, SPSS, Chicago, IL. 
The CAL measurements at the untreated control, BPBM, and BPBM + CM sites had decreased from $6.31 \pm 0.59 \mathrm{~mm}, 4.31 \pm$ $0.66 \mathrm{~mm}$, and $3.59 \pm 0.64 \mathrm{~mm}$ at 3 months after surgery to $6.09 \pm 0.57 \mathrm{~mm}, 3.54 \pm$ $0.49 \mathrm{~mm}$, and $2.89 \pm 0.22 \mathrm{~mm}$ at 72 months post-treatment, respectively. The gain in CAL at 3 months post-treatment was $0.72 \pm 0.52 \mathrm{~mm}, 2.00 \pm 0.66 \mathrm{~mm}$, and $2.72 \pm 0.62 \mathrm{~mm}$ and at 72 months after the surgical procedure it was $0.74 \pm$ $0.46 \mathrm{~mm}, 2.65 \pm 0.58 \mathrm{~mm}$, and $3.20 \pm$ $0.57 \mathrm{~mm}$ for the untreated control, BPBM, and BPBM + CM groups, respectively. Again, as with the PD reduction, a statistically significant CAL gain was noted when the two treated groups were compared to the untreated control group. Furthermore, the BPBM + CM group showed a statistically significant CAL gain compared to the BPBM group $(P<0.05)$ (Table 2).

With regard to GR, no significance difference was noted among the three groups or the different time points (Table 3 ). This was also true for the plaque index and the gingival bleeding index (Table 4).

The 6-month histologic specimens showed the presence of new bone surrounding many residual graft particles in the BPBM group (Fig. 5). For the BPBM + $C M$ group, the new bone existed with a more mature, distinguished osteoid matrix, which indicated the presence of osteoblastic activity. In addition, there were fewer residual graft particles in the BPBM + CM group compared to the BPBM group (Fig. 6).

\section{DISCUSSION}

Extraction of the deep-impacted third molar often results in periodontal intrabony defects at the distal aspect of the second molar. A few investigators ${ }^{2,20}$ even demonstrated, in a retrospective study of 215 cases, that $43 \%$ of cases had PD $\geq 7 \mathrm{~mm}$ in the adjacent second molar 2 years after surgical extraction of the impacted lower third molar. Kugelberg ${ }^{21}$ also demonstrated that the initial periodontal probing defect, the angle of the impacted molar $\left(\geq 50^{\circ}\right)$, and the age of the patient ( $\geq 25$ years) were important factors that influenced the incidence of the periodontal defects. For these reasons, the use of bioabsorbable and non-resorbable membranes have been suggested to prevent future periodontal defects during impacted third molar extraction. 7,22,23 Recently, autologous platelet-rich plasma was used to promote healing, which reduced the incidence of possible periodontal compli-

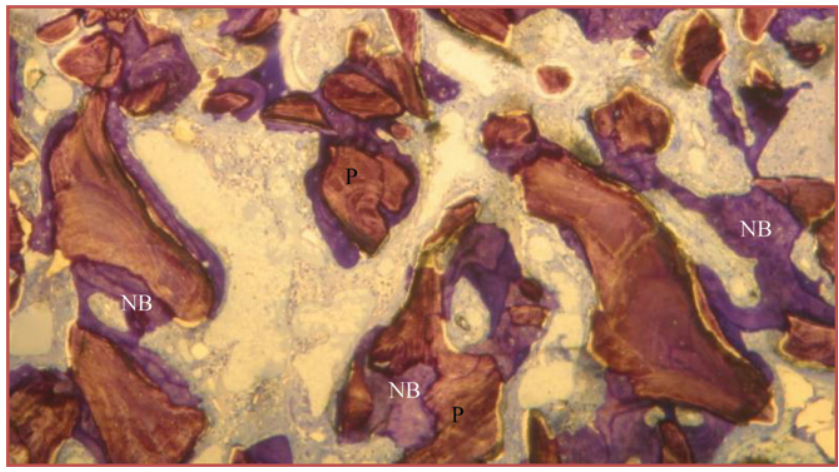

Figure 5.

Six-month histologic section shows many residual graft particles $(P)$ surrounded by new bone (NB) after BPBM treatment (acid fuchsintoluidine blue; original magnification $\times 40)$.

cations. ${ }^{24}$ The regeneration techniques proposed in this article showed that the use of BPBM, with or without a CM, is capable of preventing periodontal defects while promoting bone regeneration. 

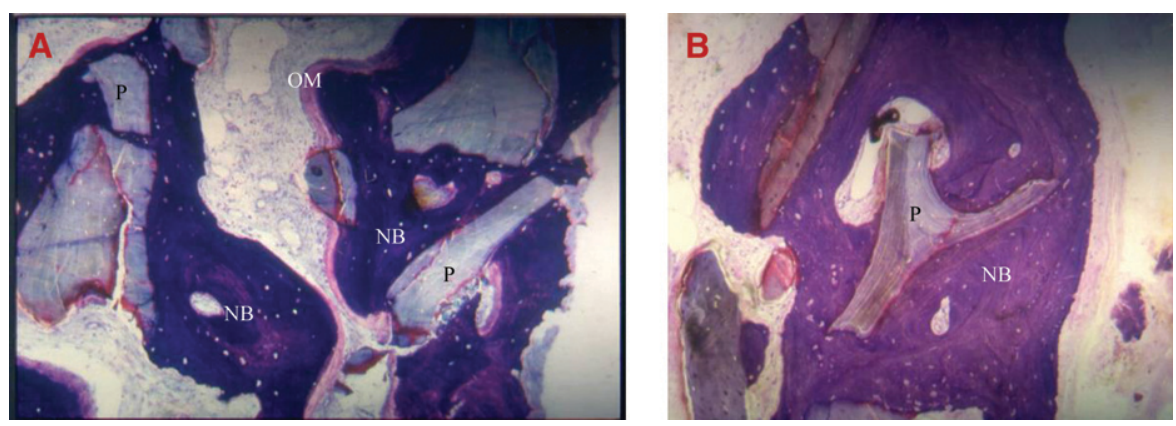

Figure 6.

$\boldsymbol{A}$ and $\boldsymbol{B})$ Six-month histologic sections show good lamellar bone formation and maturation after $B P B M+C M$ treatment (acid fuchsin-toluidine blue; original magnification $\times 40$ ). $N B=$ new bone; $P=$ particle of $B P B M ; O M=$ osteoid matrix.

BPBM was chosen for its safety, high porosity, and wide interior surface of the granules that are capable of favoring adhesion and cellular differentiation because of the penetration of the blood vessels inside. The crystalline structure and its chemical composition ensure a high compatibility with the tissues. Many studies $^{10-12,25,26}$ confirmed the efficacy of using BPBM in treating different clinical problems. A CM was selected because of its excellent biocompatibility, ease of handling, and no need for a second retrieval surgery. In addition, this CM lasts for 4 to 6 months, which is the ideal time frame for this type of defect treatment. ${ }^{10,13-16}$

The results obtained in this study support the use of either regenerative technique, especially the combination approach (BPBM + CM), to prevent future distal second-molar periodontal defects adjacent to the third molar extraction socket. Only 3 months after removal of the horizontal or mesio-angular impacted lower third molar, the BPBM and BPBM + CM groups, compared to the control sites, showed reduction in PD and gain in CAL at the second molar's distal surface adjacent to the extraction site. The reduction in PD and gain in CAL were clinically significant until 9 months after the treatment in both experimental groups, and the measurements were stable until the end of the study period (72 months). The best clinical results were noted in the BPBM+CM group. Histologic evidence at 6 months confirmed this clinical observation: a small amount of residual graft particles and a higher degree of new bone maturation were present in the BPBM + CM treatment group. This further supports the clinical improvement in PD and gain in CAL values compared to the BPBM group. A different amount of residual graft particles was also found 6 months after the surgery. Furthermore, radiographic analysis showed a greater radiopacity that was similar to the natural bone in the $\mathrm{BPBM}+\mathrm{CM}$ treatment group compared to the radio- graphic findings in the BPBM group (Fig. 4). The results remained stable over the 6-year study period in both treated groups, attesting to the long-term success of BPBM in the regenerative treatment of periodontal defects. ${ }^{27,28}$

Nevertheless, it would be desirable to have long-term histologic studies ( $>1$ year) of the healing sites to confirm the clinical and radiographic findings.

\section{CONCLUSIONS}

The application of BPBM, with or without a CM, can be a viable treatment to alleviate the periodontal defects that are often associated with deep-impacted mandibular third molar extraction. The results confirmed the long-term stability (6 years) of the proposed regenerative techniques.

\section{ACKNOWLEDGMENT}

The authors report no conflicts of interest related to this study.

\section{REFERENCES}

1. Ash MM, Costich ER, Hayward JR. A study of periodontal hazards of 3rd molars. J Periodontol 1962; 33:209-219.

2. Kugelberg CF, Ahlstrom U, Ericson S, Hugoson A. Periodontal healing after impacted lower third molar surgery. A prospective study. Int J Oral Surg 1985; 14:29-40.

3. Szmyd L, Hester WR. Crevicular depth of the second molar in impacted third molar surgery. J Oral Surg Anaesth Hosp Dent Surv 1963;21:185-189.

4. Groves BJ, Moore JR. The periodontal implications of flap design in lower third molar extractions. Dent Pract Dent Rec 1970;20:297-304.

5. Labelle RE. The influence of third molars on periodontal health. Minneap Dist Dent J 1969;53:25-28.

6. Aimetti M, Pigella E, Romano F. Clinical and radiographic evaluation of the effects of guided tissue regeneration using resorbable membranes after extraction of impacted mandibular third molars. Int $J$ Periodontics Restorative Dent 2007;27:51-59.

7. Oxford GE, Quintero G, Stuller CB, Gher ME. Treatment of 3rd molar-induced periodontal defects with guided tissue regeneration. J Clin Periodontol 1997; 24:464-469.

8. Irinakis $T$, Tabesh M. Preserving the socket dimensions with bone grafting in single sites: An esthetic surgical approach when planning delayed implant placement. J Oral Implantol 2007;33:156-163.

9. Keith JD Jr., Salama MA. Ridge preservation and augmentation using regenerative materials to enhance implant predictability and esthetics. Compend Contin Educ Dent 2007;28:614-621. 
10. Camelo M, Nevins ML, Schenk RK, et al. Clinical, radiographic and histologic evaluation of human periodontal defects treated with Bio-Oss and Bio-Gide. Int $J$ Periodontics Restorative Dent 1998;18:321-331.

11. Fugazzotto PA. GBR using bovine bone matrix and resorbable and nonresorbable membranes. Part 1: Histologic results. Int $J$ Periodontics Restorative Dent 2003;23:361-369.

12. Fugazzotto PA. GBR using bovine bone matrix and resorbable and nonresorbable membranes. Part 2: Clinical results. Int $J$ Periodontics Restorative Dent 2003;23:599-605.

13. Blumenthal N, Steinberg J. The use of collagen membrane barriers in conjunction with combined demineralized bone-collagen gel implants in human intrabony defects. J Periodontol 1990;61:319-327.

14. Camargo PM, Lekovic V, Weinlander M, Vasilic N, Madzarevic M, Kenney EB. Platelet-rich plasma and bovine porous bone mineral combined with guided tissue regeneration in the treatment of intrabony defects in humans. J Periodontol Res 2002;37:300-306.

15. Camelo M, Nevins ML, Lynch SE, Schenk RK, Simion $M$, Nevins $M$. Periodontal regeneration with an autogenous bone-Bio-Oss composite graft and a Bio-Gide membrane. Int J Periodontics Restorative Dent 2001; 21:109-119.

16. Chen CC, Wang HL, Smith F, Glickman GN, Shyr Y, O'Neal RB. Evaluation of a collagen membrane with and without bone grafts in treating periodontal intrabony defects. J Periodontol 1995;66:838-847.

17. O'Leary TJ, Drake RB, Naylor JE. The plaque control record. J Periodontol 1972;43:38.

18. Muhleman H, Son S. Gingival sulcus index. A leading symptom in initial gingivitis. Helv Odontol Acta 1971; 42:195-209.

19. Silness J, Löe H. Periodontal disease in pregnancy. II. Correlation between oral hygiene and periodontal condition. Acta Odontol Scand 1964;22:121-135.

20. Kugelberg CF, Ahlstrom U, Ericson S, Hugoson A, Thailander $\mathrm{H}$. The influence of anatomical, pathophysiological and other factors on periodontal healing after impacted lower third molar surgery. J Clin Periodontol 1991;18:37-43.

21. Kugelberg CF. Periodontal healing two and four years after impacted lower third molar surgery. A compar- ative retrospective study. Int $J$ Oral Maxillofac Surg 1990;19:341-345.

22. Karapataki S, Hugoson A, Kugelberg CF. Healing following GTR treatment of bone defects distal to mandibular 2nd molars after surgical removal of impacted 3rd molars. J Clin Periodontol 2000;27:325-332.

23. Karapataki S, Hugoson A, Falk H, Laurell L, Kugelberg CF. Healing following GTR treatment of intrabony defects distal to mandibular 2nd molars using resorbable and non-resorbable barriers. J Clin Periodontol 2000;27:333-340.

24. Sammartino G, Tia M, Marenzi G, di Lauro AE, D'Agostino E, Claudio PP. Use of autologous platelet-rich plasma (PRP) in periodontal defects treatment after extraction of impacted third molars. J Oral Maxillofac Surg 2005;63:766-770.

25. Scheyer ET, Velasquez-Plata D, Brunsvold MA, Lasho DJ, Mellonig JT. A clinical comparison of a bovinederived xenograft used alone and in combination with enamel matrix derivative for the treatment of periodontal osseous defects in humans. $J$ Periodontol 2002;73:423-432.

26. Tadjoedin ES, de Lange GL, Bronckers AL, Lyaruu DM, Burger EH. Deproteinized cancellous bovine bone (Bio-Oss) as bone substitute for sinus floor elevation. A retrospective, histomorphometrical study of five cases. J Clin Periodontol 2003;30:261-270.

27. Slotte C, Asklöw B, Lundgren D. Surgical guided tissue regeneration treatment of advanced periodontal defects: A 5-year follow-up study. J Clin Periodontol 2007;34:977-984.

28. Stavropoulos A, Karring T. Five-year results of guided tissue regeneration in combination with deproteinized bovine bone (Bio-Oss) in the treatment of intrabony periodontal defects: A case series report. Clin Oral Investig 2005;9:271-277.

Correspondence: Dr. Gilberto Sammartino, Department of Oral and Maxillofacial Sciences, Division of Oral Surgery, University of Naples, Via Pansini 5, Ed. 14, 80131, Naples, Italy. Fax: 39-81-7462654; e-mail: gilberto.sammartino@ unina.it.

Submitted October 2, 2008; accepted for publication November 10, 2008. 